Document downloaded from:

http://hdl.handle.net/10251/60095

This paper must be cited as:

Genovés Gómez, V.; Gosálbez Castillo, J.; Miralles Ricós, R.; Bonilla Salvador, MM.; Paya Bernabeu, JJ. (2015). Ultrasonic characterization of GRC with high percentage of fly ash substitution. Ultrasonics. 60:88-95. doi:10.1016/j.ultras.2015.02.016.

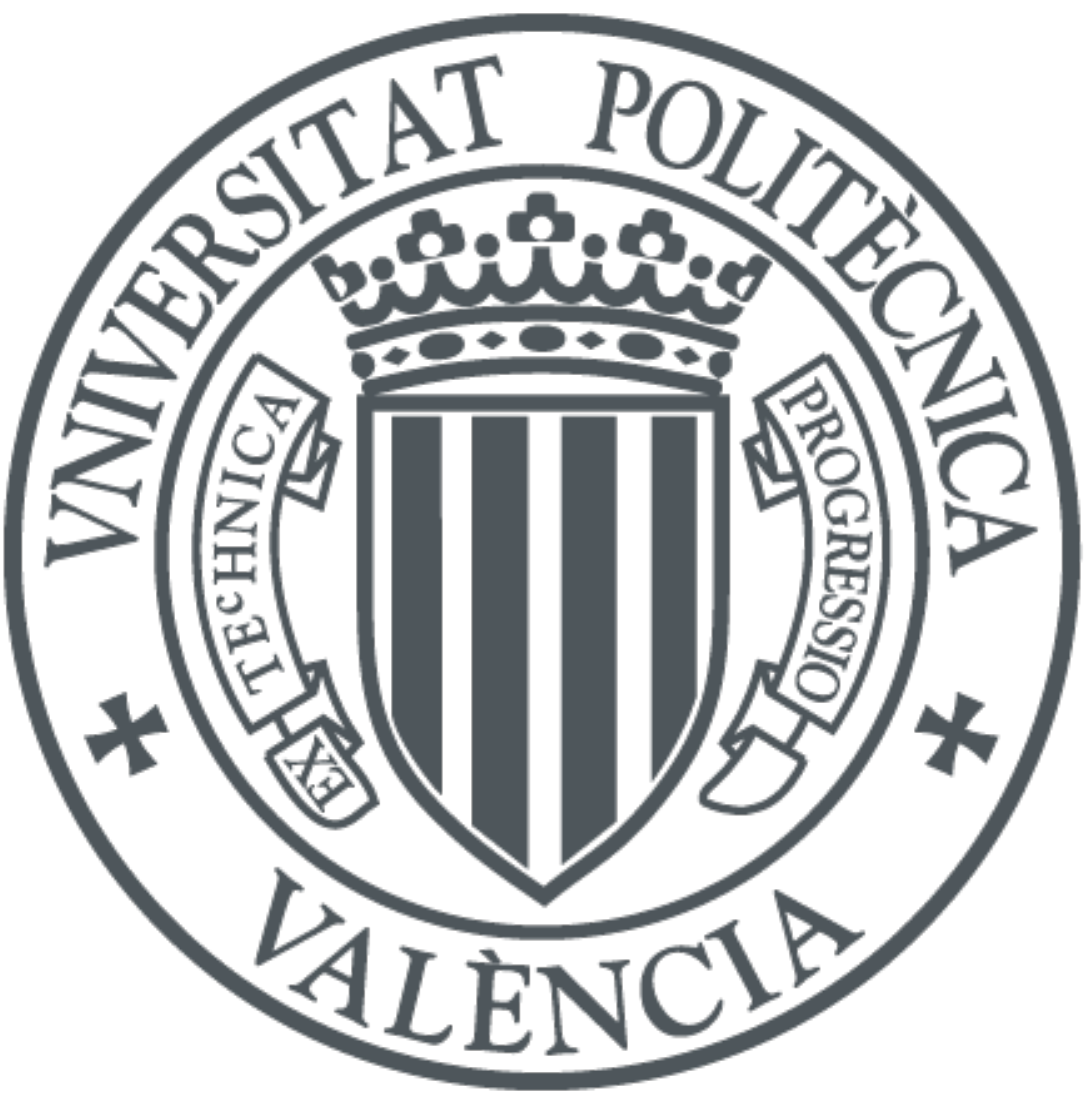

The final publication is available at

http://dx.doi.org/10.1016/j.ultras.2015.02.016

Copyright Elsevier

Additional Information 


\title{
Ultrasonic characterization of GRC with high percentage of fly ash substitution
}

\author{
V.Genovés ${ }^{\mathrm{a}, *}, \mathrm{~J}$.Gosálbez ${ }^{\mathrm{b}, * *}$, R.Miralles ${ }^{\mathrm{b}}$, M.Bonilla ${ }^{\mathrm{a}}$, J.Payáa \\ ${ }^{a}$ ICITECH, Universitat Politècnica de València, Camino de Vera, $s / n 46022$ Valencia, Spain \\ ${ }^{b}$ ITEAM, Universitat Politècnica de València, Camino de Vera, s/n 46022 Valencia, Spain
}

\begin{abstract}
New applications of non destructive techniques (NDT) with ultrasonic tests (attenuation and velocity by means of ultrasonic frequency sweeps) have been developed for the characterization of fibre-reinforced cementitious composites. According to new lines of research on glass-fibre reinforced cement (GRC) matrix modification, two similar GRC composites with high percentages of fly ash and different water/binder ratios will be studied. Conventional techniques have been used to confirm their low $\mathrm{Ca}(\mathrm{OH})_{2}$ content (Thermogravimetry), fibre integrity (Scanning Electron Microscopy), low porosity (Mercury Intrusion Porosimetry) and good mechanical properties (Compression and four points bending test). Ultrasound frequency sweeps allowed the estimation of the attenuation and pulse velocity as functions of frequency. This ultrasonic characterization was correlated successfully with conventional techniques.

Keywords:

Characterization, GRC, Fly ash, Ultrasonics, Attenuation, Pulse velocity, Frequency sweep
\end{abstract}

\section{Introduction}

Glass-fibre Reinforced Cement (GRC) is a composite made of Portland cement mortar with low water/cement (w/c) ratio with a large amount of paste in relation to the aggregate quantity. Addition of a high proportion of glass fibres to the mortar matrix (3\%-5\% by weight of mortar) improves the mechanical properties of the elements formed with this material, specially the toughness and ductility. This composite has an important role in non-steel reinforced pre-cast concrete elements such as sheets, panels and other slim shapes usually employed in building engineering and architecture, and also in cast-in-situ sprayed-on surfaces $[1,2]$.

The most important problem with this kind of material is the glass-fibre degradation. Exposure of the E-glass fibres to an alkaline environment (e.g.: the Portland cement matrix) leads to a rapid degradation process which involves strength and weight losses, and reduction in the filament diameter. This process can

\footnotetext{
*Corresponding author E-mail adress: genoves.gomez@gmail.com

** Corresponding author E-mail adress: jorgocas@dcom.upv.es
} 
be attributed to the breaking of the $\mathrm{Si}-\mathrm{O}-\mathrm{Si}$ bonds in the glass network, by the $\mathrm{OH}^{-}$ions which are present

in high concentration in the pore solution of the cement matrix [2, 3].

For that reason, research on this topic has focused on three main lines:

1. Fibre modification, making it more stable to a highly alkaline environment;

2. Matrix modification, adding moderate quantities of pozzolanic powders partially substituting for the Portland cement content;

3. Fibre and matrix modification at the same time.

As to fibre modification investigations, research has focused on modifying the chemical composition of the glass(e.g.: $\mathrm{ZrO}_{2}$ ), which makes the system more chemically stable in alkaline solutions [3, 4], and fibre-coating modification $[5,6]$.

As to matrix modification, several authors have reported successful results by means of the partial replacement of cement by reactive mineral admixtures such as silica fume, fly ash, metakaolin or blast-furnace slag. These modifications of the matrix have resulted in an improvement of the fibre-matrix interface, partially inhibiting fibre degradation due to the reduction of the $\mathrm{pH}$ level and the $\mathrm{Ca}(\mathrm{OH})_{2}$ content [7-10]. Thus the mechanical properties of the GRC specimens are improved significantly. Usually, the characterization of this kind of cement composite is carried out through conventional techniques such as x-ray diffraction, thermogravimetry, and mechanical tests $[10,11]$.

Recently, several researchers have focused on non-destructive concrete and mortar characterization in order to obtain more reliable information and new aspects of cementitious composites without damaging the specimen under test. During recent years, Non-Destructive Techniques (NDT) applied on concrete have been investigated, especially ultrasonics and acoustic spectroscopy, in order to obtain parameters related to the physical and mechanical properties of the material [12]. Some experimental studies have demonstrated that wave parameters such as the ultrasonic pulse velocity of P-waves are suitable to predict the dynamic elastic modulus of concrete and also S-waves for dynamic shear modulus. These parameters are proportional to the elastic and shear modulus of concrete and also to its compressive strength [13, 14]. Other studies based on ultrasound propagation indicate that wave attenuation can be measured for various frequencies, in order to define different cementitious materials, distinguishing the microstructure, porosity, and other qualities in both the hardened [15-18] and the fresh state [19]. Some studies have shown interesting correlations between other properties of cementitious composites, such as their permeability or porosity, with ultrasonic parameters such as pulse velocity, signal attenuation, or reflection coefficients, using a specific test setup

NDT techniques for characterizing GRC specimens had been applied: acoustic resonance techniques (Non-linear Impact Resonance Acoustic Spectroscopy, NIRAS) and ultrasonic guided waves have been used to obtain more information about the composite material and its ageing process than traditional tests on GRC [21]. The scope of this study is to characterize GRC specimens with high substitutions of the cement content 
by fly ash. As a novelty for fibre-reinforced cementitious composites, the characterization will be carried out by means of ultrasonic frequency sweeps that will allow obtaining ultrasonic parameters as a functions of the frequency. The frequency response will be correlated with the porosity and the mechanical behaviour of this type of material. Thermogravimetry and scanning electron microscopy will be used to assess the pozzolanic reaction and fibre integrity.

\section{Experimental}

\subsection{Materials}

Two different matrices with the same type of glass fibre and content were designed, as can be seen in Table 1. In both mixtures the proportion of Portland cement to fly ash was 40/60.

Table 1: Dosages (in grams) used on GRC plate manufacturing

\begin{tabular}{llll}
\hline Material & Type & fa-035 $[\mathrm{g}]$ & fa-030 [g] \\
\hline Cement & CEM I 52,5-R & 726 & 726 \\
Fly Ash & $\mathrm{F}^{*}$ & 1089 & 1089 \\
Water & - & 635.25 & 544.50 \\
Aggregate & Silica sand 0/2 & 1216 & 1216 \\
Superplastizicer & Policarboxilate ether & 3.50 & 7 \\
Fibre & Glass AR 12 mm $\varnothing 12 \mu \mathrm{m}$ & 73.50 & 73.50 \\
\hline
\end{tabular}

ASTM C-618

** Cem-FIL ${ }^{\circledR} 6282 \mathrm{Tex}$

The raw materials and their brief description are summarized in Table 1. The main difference between both composites was the water/binder (w/b) ratio: fa- 035 corresponds to $0.35 \mathrm{w} / \mathrm{b}$ ratio whereas fa-030 corresponds to $0.30 \mathrm{w} / \mathrm{b}$ ratio. The plates used for the ultrasonic tests and the four-point bending test were manufactured according to the BS EN 1170-5 standard [22]. In this experiment, $400 \times 400 \times 20 \mathrm{~mm}^{3}$ mother plate was chosen, according to the standard , 7 specimens of $325 \times 50 \times 20 \mathrm{~mm}^{3}$ were prepared by cutting of the hardened mother plate. Three mortar specimens of each series ( $40 \times 40 \times 160 \mathrm{~mm}^{3}$ ) were manufactured for the compressive strength test. A sample of each series was taken for Mercury Intrusion Porosimetry (MIP). For the thermogravimetry tests, pastes with neither fibres nor sand were made. The plate manufacturing process was carried out on mixing the raw materials following the next procedure:

1. $60 \mathrm{~s}$ of mixing water $+2 / 3$ superplasticizer + cement + fly ash

2. $30 \mathrm{~s}$ of adding sand and mixing

3. $30 \mathrm{~s}$ adding $1 / 3$ superplasticizer

4. $60 \mathrm{~s}$ mixing mortar

5. $60 \mathrm{~s}$ adding fibre and mixing 
Table 2: Cement and fly ash composition by \% weight

\begin{tabular}{lllllllllllll}
\hline Component & $\mathrm{LOI}^{*}$ & $\mathrm{SiO}_{2}$ & $\mathrm{Al}_{2} \mathrm{O}_{3}$ & $\mathrm{Fe}_{2} \mathrm{O}_{3}$ & $\mathrm{CaO}$ & $\mathrm{MgO}$ & $\mathrm{SO}_{3}$ & $\mathrm{~K}_{2} \mathrm{O}$ & $\mathrm{C}_{4} \mathrm{AF}$ & $\mathrm{C}_{3} \mathrm{~A}$ & $\mathrm{C}_{3} \mathrm{~S}$ & $\mathrm{C}_{2} \mathrm{~S}$ \\
\hline CEM I-52,5 R & 2.05 & 20.52 & 3.37 & 3.92 & 63.36 & 1.96 & 2.59 & 0.99 & 11.93 & 2.33 & 55.7 & 16.94 \\
Fly ash type F & 1.97 & 49.91 & 25.80 & 13.94 & 3.84 & 1.06 & 1.00 & 2.47 & - & - & - & - \\
\hline
\end{tabular}

* Loss on ignition

The mechanical and the non-destructive tests were performed 90 days after the plates were manufactured, in order to allow the completion of any hydration and pozzolanic reactions in the matrix. All the specimens were cured in a wet chamber at $20^{\circ} \mathrm{C}$ and $100 \% \mathrm{RH}$.

Table 2 gives details of the cement and fly ash chemical composition. As can be observed, the fly ash contains a large amount of $\mathrm{SiO}_{2}$ and $\mathrm{Al}_{2} \mathrm{O}_{3}$ (the sum of these oxides was higher than $75 \%$ ), important components for the progress of a pozzolanic reaction.

\subsection{Test methodology}

Several tests were done on this study in order to compare the performance of ultrasonic tests and other characterization techniques. Mechanical tests (INSTRON universal testing machine, model 3382), Scanning Electron Microscopy (JEOL JSM 6300 aplying a 20kV voltage), Mercury Instrusion Porosimetry (AutoPore IV 9500 of Micrometrics Instrument Corporation with a range of pressures between 13,782 $\mathrm{Pa}$ and 227.4 MPa) and Thermogravimetry (Mettler TGA 850).

\subsubsection{Ultrasonic and equipment test description}

An ultrasonic through-transmission setup was selected because it offers good penetration and good accuracy for velocity and attenuation estimation ([15, 23-25]). The disposition of the equipment is shown in Fig. 1. The transducers used were the K1SM (for transmission) K1SC (for reception) General Electric. Both are broadband transducers with a bandwidth centered at $1 \mathrm{MHz}$.

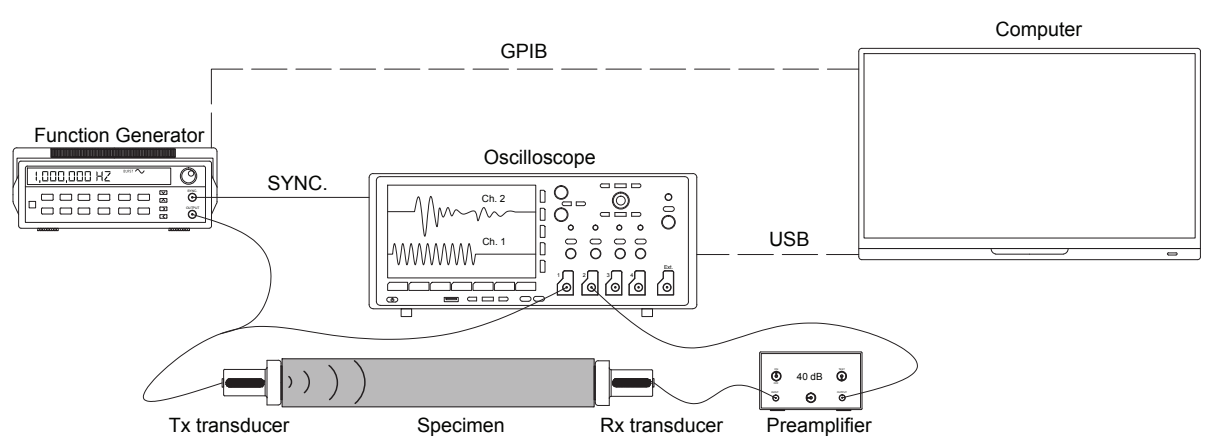

Figure 1: Ultrasonic equipment layout

The transmitter transducer was excited directly by a programmable signal generator (Agilent 33120A) while the reception transducer was connected to a $40 \mathrm{~dB}$ preamplifier (Panametrics $5600 \mathrm{~B}$ ). The received 
and amplified ultrasonic signal was captured by a digital oscilloscope (Tektronix DPO3014) with a sampling frequency of $25 \mathrm{MHz}$. Finally, a laptop was used to control the signal generator and to acquire and store the digitized signals by the oscilloscope.

The ultrasonic transducers were placed facing the longitudinal axis of the specimen as shown in Fig. 2 . They were fixed by two plastic clamps: a movable one to adjust to the specimen, and a fixed one. Ultrasonic gel was used as an impedance coupling medium between the transducers and the specimen.

The emitter transducer was excited by means a sinusoidal tone burst generated by the signal generator (see Fig. 3). From this signal, different ultrasonic parameters can be estimated. As is explained in Appendix A, the main set-up parameters of the tone burst signal are: fundamental frequency $f_{0}$, amplitude of the signal $A_{0}$, the number $N$ of periods included in the burst, and the repetition period $T_{P R F}$.

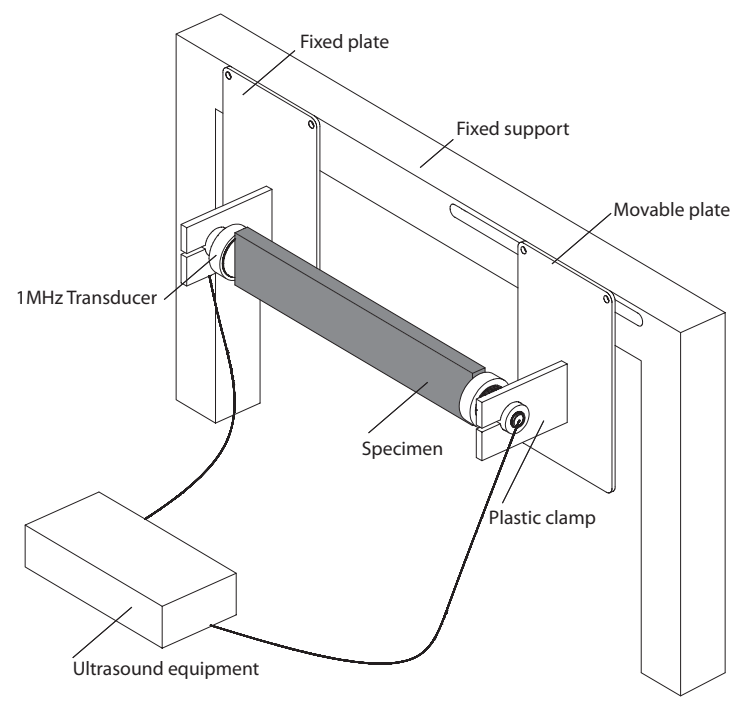

Figure 2: Tests disposition: specimen and ultrasonic transducers

The transmitted signal propagates through the specimen and is altered by its physical and mechanical properties and also by the measurement equipment. Comparing the transmitted and the received signals (see Fig. 3), allows of assessing the ultrasonic propagation parameters. Taking into account that most of the tone burst energy is concentrated around its fundamental frequency (see Appendix A), it is possible to obtain ultrasonic curves doing a frequency sweep of the tone burst $f_{0}$.

The selected values for the transmitted signal were: $A_{0}=10 \mathrm{~V}, N=5$, and $T_{P R F}=20 \mathrm{~ms}$. The signal generator was set to sweep the fundamental frequency of the tone burst, $f_{0}$, from $1 \mathrm{kHz}$ up to $1 \mathrm{MHz}$ with increments of $5 \mathrm{kHz}$ and a delay of $1 \mathrm{~s}$ between each analysed frequency. Therefore, for each specimen, 200 measurements were acquired (one for each fundamental frequency) and a frequency response of 200 points is obtained for each ultrasonic parameter. Specifically, the p-wave velocity $\left(v_{p}[\mathrm{~m} / \mathrm{s}]\right)$ and attenuation $(\alpha$ $[\mathrm{dB} / \mathrm{cm}])$ were the ultrasonic parameters for this analysis $[15,26]$. 


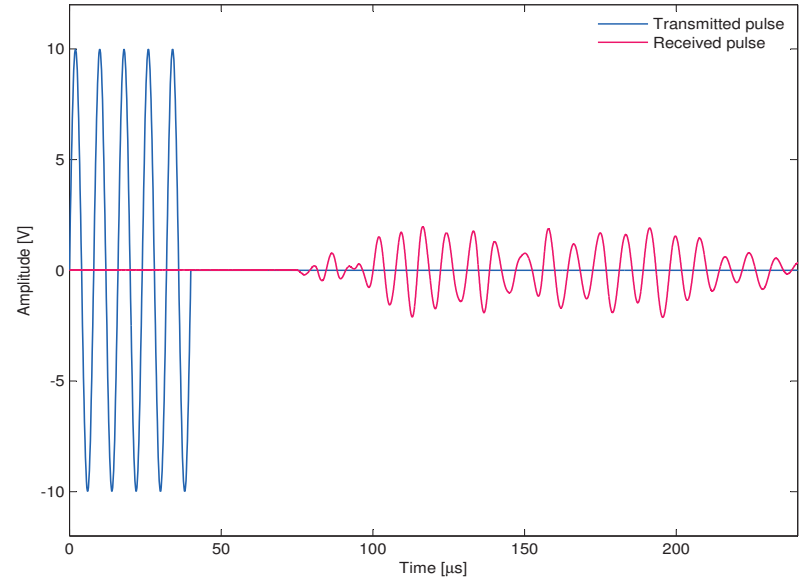

Figure 3: Transmitted and received tone burst

$v_{p}$ is obtained as the ratio between the length of the specimen, $d_{\text {mat }}$, and the signal time arrival, $t_{a}$, Eq. (1). The $t_{a}$ was estimated as the time when the received signal $\left(x_{f_{0}}^{(r x)}(t)\right)$ level exceeds $20 \%$ of the noise

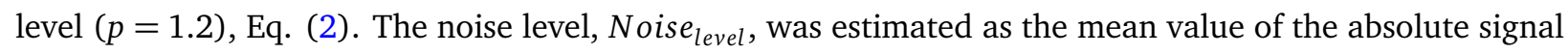
at first $t_{d}=20 \mu$ s, Eq. (3).

$$
\begin{gathered}
v_{p}\left(f_{0}\right)=\frac{d_{\text {mat }}}{t_{a}} \\
\left|x_{f_{0}}^{(r x)}\left(t_{a}\right)\right|>p \cdot \text { Noise }_{\text {level }} \\
\text { Noise }_{\text {level }}=\frac{1}{t_{d}} \int_{0}^{t_{d}}\left|x_{f_{0}}^{(r x)}(t)\right| d t
\end{gathered}
$$

Additionally, the attenuation of the material, $\alpha_{\text {mat }}\left(f_{0}\right)[\mathrm{dB} / \mathrm{cm}]$, was obtained as the difference between transmitted energy, $E_{t x}\left(f_{0}\right)[\mathrm{dB}]$ and the received energy, $E_{r x}\left(f_{0}\right)[\mathrm{dB}]$, plus attenuation due to the equipment, $\alpha_{\text {equip }}\left(f_{0}\right)[\mathrm{dB}]$, divided by the total length of the specimen, $d_{\text {mat }}[\mathrm{cm}]$, Eq. (4). $E_{t x}\left(f_{0}\right)$ is obtained theoretically from Eq. (A.6), meanwhile $E_{r x}\left(f_{0}\right)$ was obtained from received signal in frequency domain from Eq. (A.5). The $\alpha_{\text {equip }}\left(f_{0}\right)$ is associated to the frequency response of the measurement equipment (transducers, amplifier, cables, acquisition module,...) and is independent of the tested material. Therefore a calibration process is required.

$$
\alpha_{\text {mat }}\left(f_{0}\right)=\frac{E_{t x}\left(f_{0}\right)-E_{r x}\left(f_{0}\right)+\alpha_{\text {equip }}\left(f_{0}\right)}{d_{\text {mat }}}
$$

The calibration process was carried out with the emitter and receiver transducers face to face without any material between them. In this situation, Eq. (4) simplifies to Eq. (5) due to the absence of the material. 
The testing process was similar to the material analysis except that the input signal was reduced up to $0.5 V_{p}$

to avoid saturation.

$$
\alpha_{\text {equip }}\left(f_{0}\right)=E_{t x}\left(f_{0}\right)-E_{r x}\left(f_{0}\right)
$$

Fig. 4 shows the $-\alpha_{\text {equip }}\left(f_{0}\right)$ which was obtained from the calibration process. This curve was used to compensate the received energy during the normal measurement process.

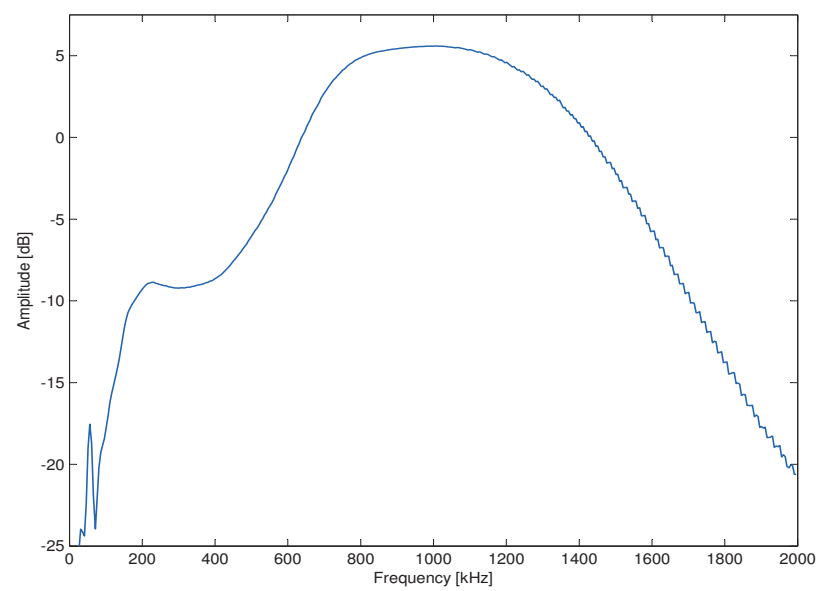

Figure 4: Frequency response of the measurement module $\left(-\alpha_{\text {equip }}\left(f_{0}\right)\right)$ during the calibration process

\section{Results and discussion}

\subsection{Mechanical results}

The specimens used for compression test were 40x40x160 $\mathrm{mm}^{3}$ according to UNE-EN-1015-11 standard were manufactured without fibres in order to obtain the compressive strength of the matrix and extract some fragments to analyse by means Mercury Intrusion Porosimetry (MIP) technique. The specimens used for four points flexural test were $325 \times 50 \times 20 \mathrm{~mm}^{3}$ according to BS EN 1170-5.

Table 3: Parameters obtained from mechanical tests

\begin{tabular}{lllll}
\hline Serie & $\sigma_{\text {comp }}[\mathrm{Mpa}]$ & $\sigma_{\text {flex }}[\mathrm{Mpa}]$ & $E c[\mathrm{GPa}]$ & Work of fracture $[\mathrm{Nmm}]$ \\
\hline fa - 030 & $92.2 \pm 2.2$ & $10.9 \pm 1.2$ & $20 \pm 2$ & $882 \pm 174$ \\
fa - 035 & $86.1 \pm 4.1$ & $14.0 \pm 0.6$ & $19 \pm 2$ & $1926 \pm 232$ \\
\hline
\end{tabular}

Specimens used for bending test were extracted from a 400x400x20 $\mathrm{mm}^{3}$ mother plate and used to obtain work of fracture $[\mathrm{Nmm}]$, maximum flexural strength $\sigma_{\text {flex }}[\mathrm{MPa}]$ and elastic modulus $E c_{\text {flex }}[\mathrm{GPa}]$. Mechanical data are summarized in Table 3. 


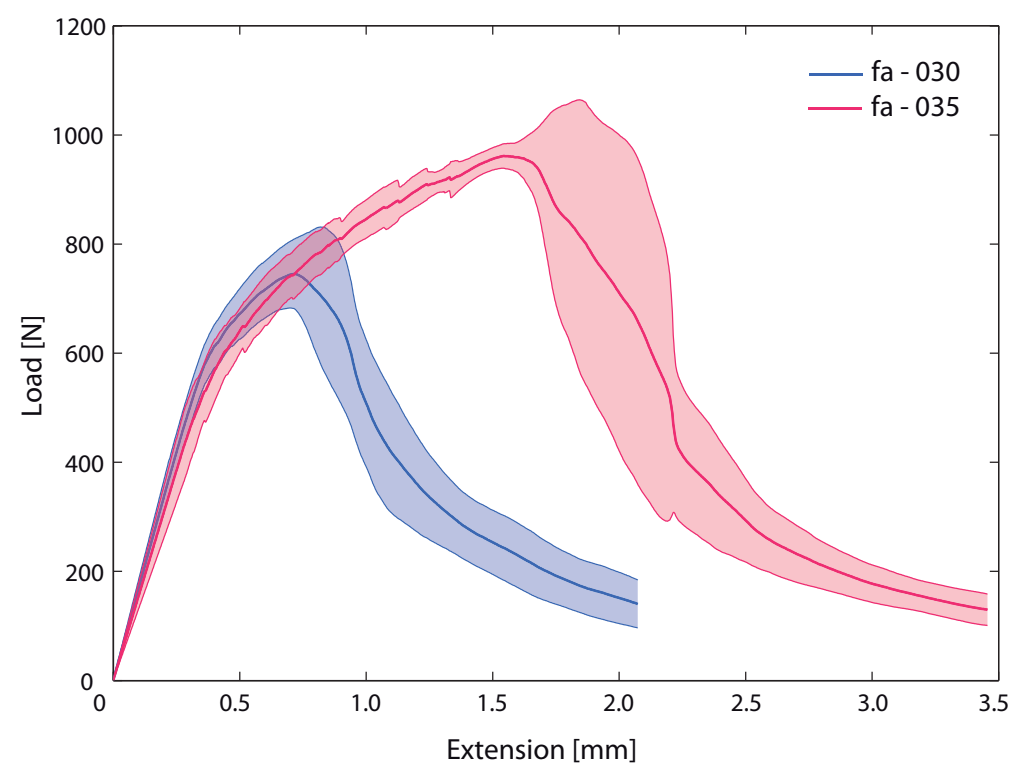

Figure 5: Load vs. extension curves for both series. Mean value of the parameters is represented by a coarse line. The shaded area represent the $90 \%$ confidence interval

Obtained mechanical results showed different properties between both series. Compressive strength on fa-030 was higher than compressive strength on fa-035: lower w/b ratios make the material more compact and better for compressive tensions. Flexural strength on fa-035 was higher because the specimen suffers high tensile tensions on the lower fibre of the element and the glass fibre begins to work.For this type of composites, the reduction of $\mathrm{w} / \mathrm{b}$ ratio produces a more rigid matrix yielding a more brittle fracture. Additionally, fibres distribute better the tensile stresses into a more ductile matrix. The work of fracture calculated from curves showed in Fig. 5 demonstrated the best behaviour in toughness for fa-035 series.

\subsection{Thermogravimetry results}

After mixing raw components of the pastes, the samples were kept in closed containers at $20{ }^{\circ} \mathrm{C}$. At 28 and 90 days of curing, portions of the samples were taken and pulverized with an agate mortar adding a small amount of acetone. The solid was filtered and dried at $60{ }^{\circ} \mathrm{C}$ for 15 minutes. These samples are studied by means of the thermogravimetric analysis. Sealed aluminium crucibles of $100 \mu \mathrm{m}$ were used with a lid that has a micro hole to create a water vapour self-generated atmosphere. The analysis was carried out in dry nitrogen atmosphere with a flow of $75 \mathrm{~mL} / \mathrm{min}$, a heating rate of $10^{\circ} \mathrm{C} / \mathrm{min}$, and a temperature range of 35 to $600{ }^{\circ} \mathrm{C}$. Thermogravimetry test was performed on samples to check the pozzolanic reaction progression between $\mathrm{Ca}(\mathrm{OH})_{2}$ (portlandite) produced from the hydration of the Portland cement and fly ash. As commented before, the pozzolanic reaction has a moderated importance in order to reduce matrix $\mathrm{pH}$ and $\mathrm{Ca}(\mathrm{OH})_{2}$ consumption enhancing the chemical stability of the glass fibre.

Fig. 6 shows thermogravimetric analysis (derivative curves, DTG) for fa-035 and control material manufactured without fly ash and same w/b ratio. DTG curve for fa-030 was very similar to fa-035 one and it was 
Table 4: Thermogravimetric paramters for 90 days cured pastes

\begin{tabular}{llllll}
\hline Serie & Total loss [\%] & $\mathrm{Ca}(\mathrm{OH})_{2}[\%]$ & Hydrates [\%] & Combined $\mathrm{Ca}(\mathrm{OH})_{2}[\%]$ & $\%^{*} \mathrm{Ca}(\mathrm{OH})_{2}$ \\
\hline control & 18.36 & 9.41 & 16.07 & - & 100 \\
fa - 030 & 12.68 & 1.44 & 12.33 & 65.82 & 15.28 \\
fa - 035 & 15.75 & 1.89 & 15.29 & 55.08 & 20.08 \\
\hline
\end{tabular}

* Respect to the control

not plotted for clarity. Control sample was necessary for calculating the percentage of portlandite fixation. Portlandite fixation parameters are shown in Table 4. As can be observed, both series (fa-030 and fa-035) have high percentage (55\% - 65\%) of combined $\mathrm{Ca}(\mathrm{OH})_{2}$, indicating an important pozzolanic activity on fly ash. Matrices containing fly ash have only $15-20 \%$ of $\mathrm{Ca}(\mathrm{OH})_{2}$ respect to the control, and consequently chemical stability of fibres is enhanced.

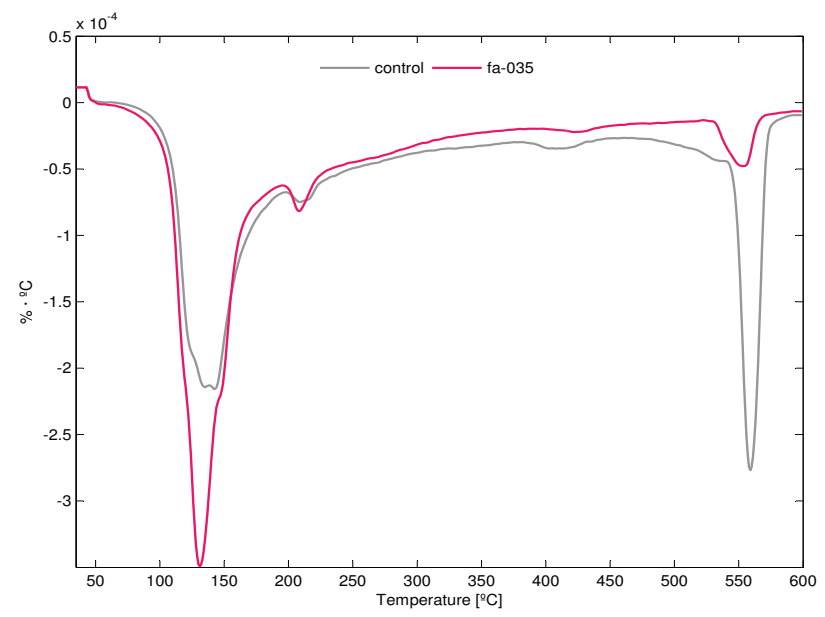

Figure 6: Thermogravimetry analysis of matrix samples and cement control

\subsection{Mercury Intrusion Porosimetry}

Due to the relevance of capillary net, pores and density, tests using Mercury Intrusion Porosimetry were performed in both series to allow comparison with ultrasonic parameters.

In Fig. 7, fa-030 and fa-035 pore distribution curves are shown. fa-035 shows a more porous structure than fa-030. This behaviour is due to fa-035 has a higher water to binder ratio than fa-030. In addition, fa-030 has slightly different pore sizes than fa-035: fa-030 curve shift to smaller pore sizes respect to fa-035 curve.

MIP data are summarized in Table 5. Mortar prepared with highest $\mathrm{w} / \mathrm{b}$ ratio (fa-035) showed highest total porosity and lowest bulk density due to more water was not chemically combined as hydration/pozzolanic products. These results, as will be seen on Section 3.5, correlates with ultrasonic characterization and also with mechanical test data. 


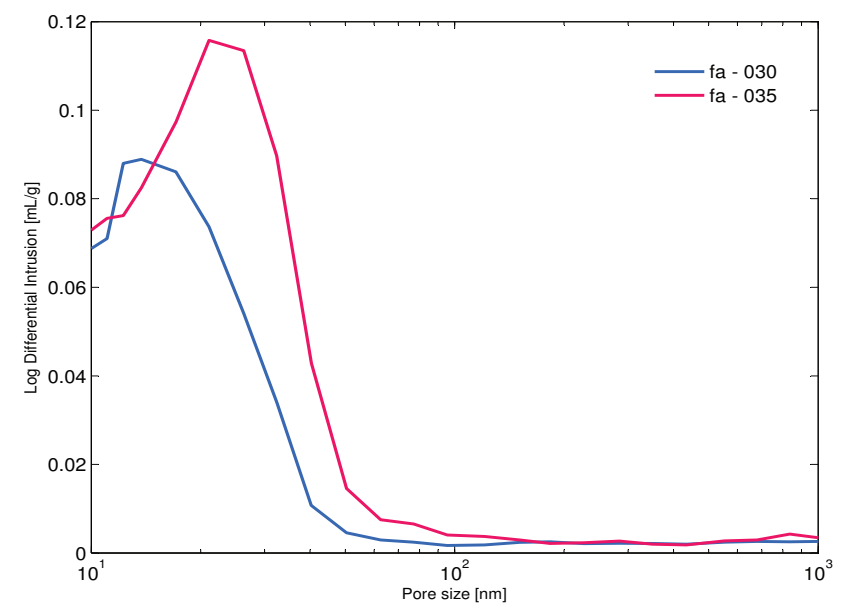

Figure 7: Pore distribution curves of both series tested without fibres

Table 5: MIP obtained parameters

\begin{tabular}{llll}
\hline Serie & Total porosity [\%] & Bulk density $[\mathrm{g} / \mathrm{mL}]$ & Median pore diameter $[\mathrm{nm}]$ \\
\hline fa -030 & 15.07 & 1.96 & 18.3 \\
fa - 035 & 18.29 & 1.89 & 22.2 \\
\hline
\end{tabular}

\subsection{Scanning Electron Microscopy observations}

Visual observations were performed with SEM on GRC specimens to verify that pozzolanic products were formed and glass fibres were embedded properly into the matrix.

In Fig. 8a, it can be observed that fibres were perfectly surrounded by the matrix and several hydration and pozzolanic products were also found. Fig. $8 \mathrm{~b}$ shows more detailed view of the fibres with unreacted fly ash on top of the fibres. Pozzolanic reaction had a successfully progression as it was observed previously on thermal analysis but a small amount of these particles did not react. Both images correspond to fa-035 specimen because there was no substantial differences between fa-035 and fa-030 on SEM as expected. In figures $8 \mathrm{c}$ and $8 \mathrm{~d}$ detailed views of glass fibre surfaces can be seen. Is important to highlight that the fibres are not attacked by the matrix.

\subsection{Ultrasonics results}

The velocity, $v_{p}\left(f_{0}\right)$, and attenuation, $\alpha_{\text {mat }}\left(f_{0}\right)$, responses of the specimens are shown in Fig. 9 and Fig. 10 respectively.

From Fig. 9 velocity can be considered to be constant over a large frequency range [15]. The velocity dependence at low frequencies $(0-200 \mathrm{~Hz})$ is due to velocity estimation algorithm which detects, by the increase of the signal level over a threshold, the arrival time of the signal, $t_{a}$. Due to that the slope of the signal is smaller for low frequencies, the increment of the level signal is also slower. Therefore the detected 


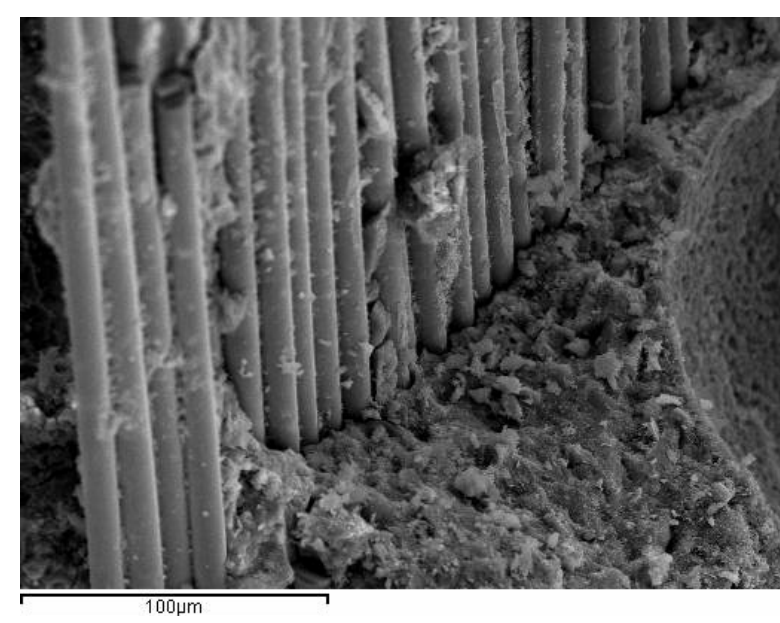

(a) x500 magnification glass fibre embedded on matrix

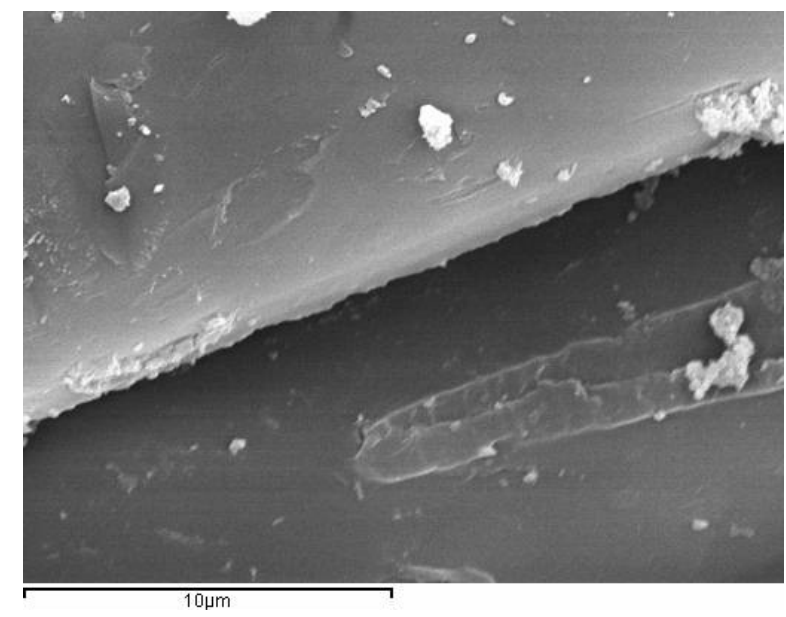

(c) x6000 magnification glass fibre surface detail

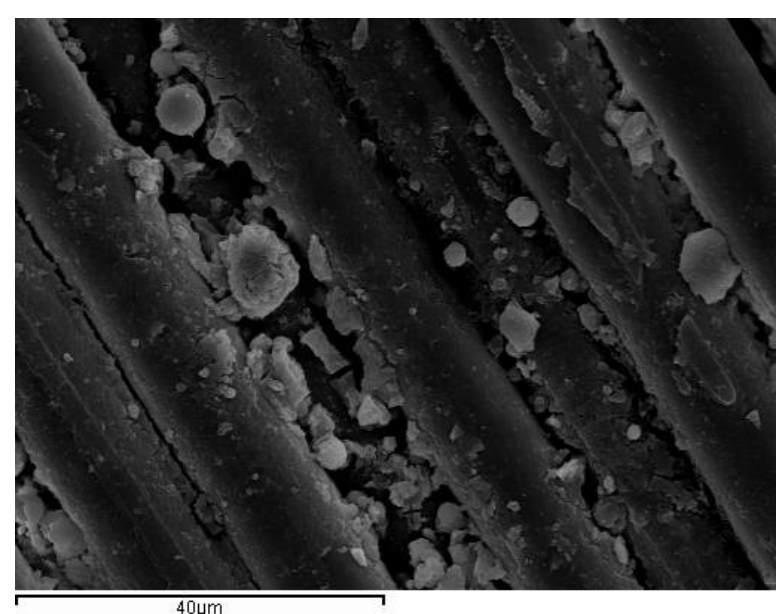

(b) x1500 magnification glass fibre with unreacted fly ash spheres

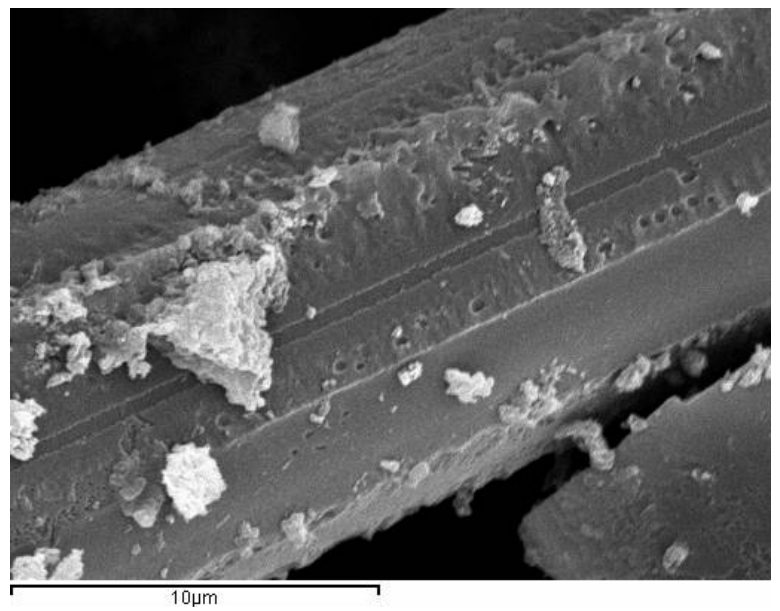

(d) x6000 magnification glass fibre surface detail

Figure 8: SEM observations with different magnification of the GRC specimens

arrival time is higher than the real one and the velocity measurement are lower than expected. Over $200 \mathrm{kHz}$, this effect can be neglected and a precise estimation of velocity is obtained. Taking into account this fact, we can assume that primary velocity response is mainly plane for both specimens although a systematic difference exists between them. For fa-030, the mean velocity is $v_{p}=4639 \pm 29 \mathrm{~m} / \mathrm{s}$ meanwhile, for fa-035, it is $200 \mathrm{~m} / \mathrm{s}$ lower $\left(v_{p}=4435 \pm 19 \mathrm{~m} / \mathrm{s}\right)$. This result is consistent with the mechanical analysis which offers a higher compressive strength for fa-030. It also indicates that fa-030 yields a higher modulus of elasticity than fa-035. $E_{c}$, which it is also consistent with the calculated $E_{c}$ from stress-strain curve, $20 \mathrm{Gpa}$ for fa-030 and 19 Gpa for fa -035 .

The attenuation response for both specimens (Fig. 10) shows that fa-035 specimens present a general higher attenuation than fa-030 specimens. Taking into account that both of them have very similar matrix, 


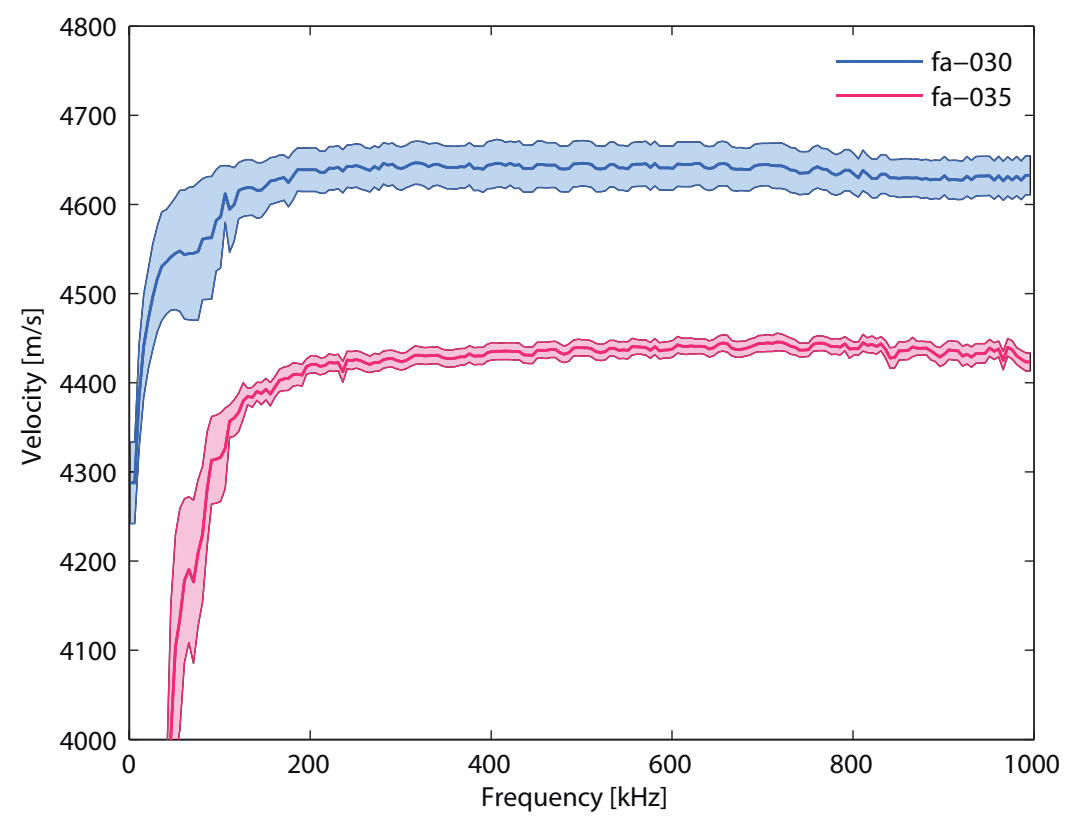

Figure 9: Velocity response versus frequency. Mean value of the parameters is represented by a coarse line. The shaded area represent the $90 \%$ confidence interval.

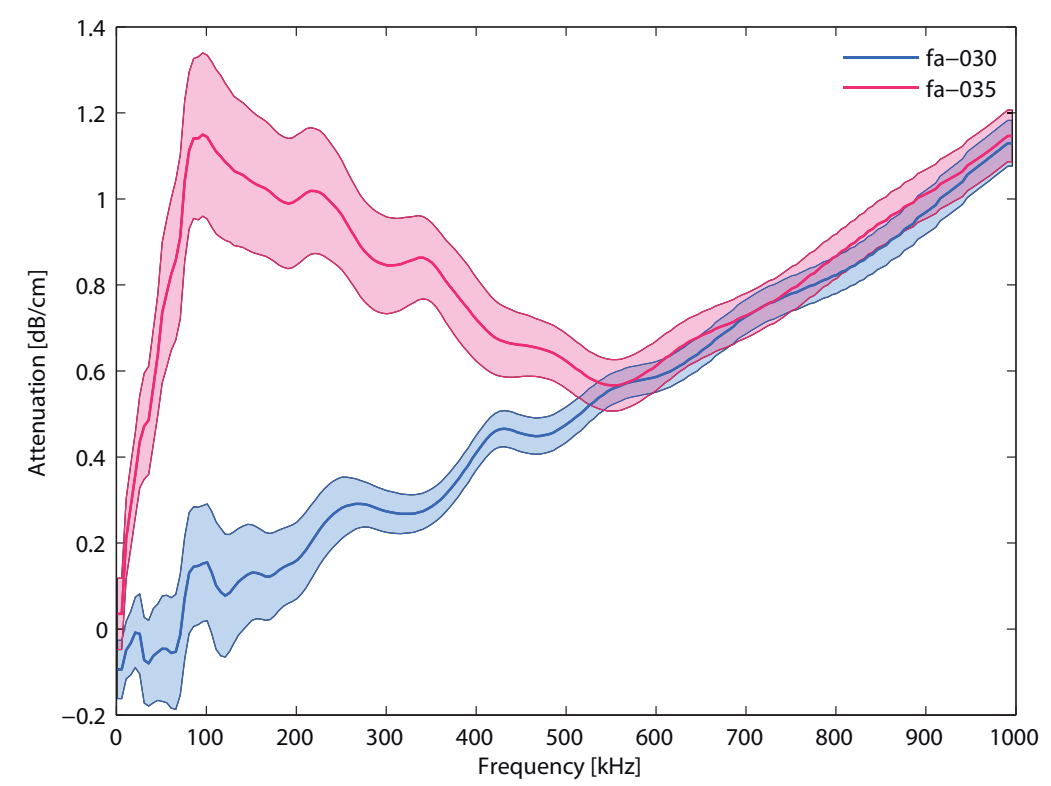

Figure 10: Attenuation response versus frequency. Mean value of the parameters is represented by a coarse line. The shaded area represent the $90 \%$ confidence interval

pore size of fa-035 is greater than average pore size of fa-030 as it is shown in Table 5 . Therefore the attenuation for Rayleigh and stochastic zones $(<550 \mathrm{kHz})$ is higher for fa-035 as it is shown in Fig. 10. For frequencies over $550 \mathrm{kHz}$ (diffusion region, [15, 24]), both specimens converge with a similar linear positive 
dependence.

\section{Conclusions}

Two glass fibre reinforced cementitious materials (GRC) with different porosity and mechanical properties were evaluated using different techniques. It has been demonstrated that ultrasonic test allows to distinguish both materials and provides additional information of material behaviour and mechanical parameters. The attenuation curves could be used to establish a relationship with the porosity parameters and some mechanical properties extracted from four point bending test. P-wave velocity was also stable and indicated a strong relationship with elastic modulus.

\section{Acknowledgments}

This work has been supported by Spanish Administration under grant TEC2011-23403 01/01/2012

\section{Appendix A. Burst Signal}

The mathematical model of a tone burst signal is shown in Eq. (A.1), where a sinusoidal signal, $A_{0} \sin \left(2 \pi f_{0} t\right)$, is active for a specific period of time $\left(N T_{0}\right)$. This is repeated periodically obtaining Eq. (A.2). The main parameters of this signal are: $T_{0}$ is the period of the fundamental frequency $\left(f_{0}=1 / T_{0}\right), A_{0}$ is the amplitude of the signal, and $N$ is the number of periods included in the burst and $T_{P R F}$ is the repetition period. In Fig. A.1, it is shown an example of a tone burst signal.

$$
\begin{gathered}
x(t)=\left\{\begin{array}{l}
A_{0} \sin \left(2 \pi f_{0} t\right), 0<t<N T_{0} \\
0, \text { otherwise }
\end{array}\right. \\
x_{\text {periodic }}(t)=\sum_{k=-\infty}^{\infty} x\left(t-k T_{P R F}\right)
\end{gathered}
$$

The real model used for experiments corresponds to Eq. (A.2) because burst signal is repeated periodically and the signal should be power defined. Despite of this, oscilloscope captures just a few microseconds, $t_{\text {capture }}$ and signal is cut off and limited in time. As a result of this, the acquired signal is finite time duration and it is defined in energy . Therefore, Eq. (A.1) will be the expression for theoretical analysis and $T_{P R F}$ will not have influence in operations provided it will be bigger than capture time of the oscilloscope. This last condition is satisfied in this analysis because $T_{P R F}=20 \mathrm{~ms}$ and $t_{\text {capture }}=100 \mu \mathrm{s}$.

The theoretical energy of a burst signal is Eq. (A.3). It is important to take into account the following facts: firstly, the transmitted energy depends on its fundamental frequency, $f_{0}$. Secondly, the energy is not completely concentrated on its fundamental frequency, $f_{0}$, but it is distributed over a bandwidth. If the Fourier Transform is applied to Eq. (A.1), we obtain the spectrum of the burst signal, Eq. (A.4), for positive 


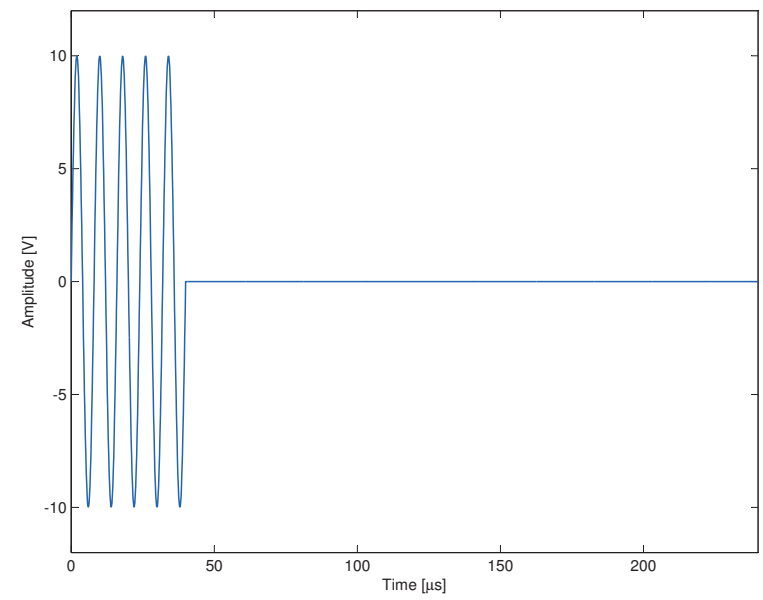

Figure A.1: Tone burst signal: $f_{0}=125 \mathrm{kHz}, A_{0}=10, N=5$

245 frequencies. The module of $X(f)$ is represented in Fig. A.2. For these reasons, the energy of the transmitted and received signals will be calculated from the spectrum over a bandwidth following Eq. (A.5) [27]. The bandwidth has been chosen to correspond to the main lobe of the spectrum, $f_{0} \pm \frac{f_{0}}{N}$. If the theoretical expression of the spectrum, Eq. (A.4), is used in Eq. (A.5), a theoretical expression for the transmitted energy is obtained, Eq. (A.6). This expression also depends on $f_{0}$. The ratio between the bandwidth energy, Eq. 250 (A.6), and total energy, Eq. (A.3), is a constant ratio of 0.9 that it means that the $90 \%$ of energy concentrates over the main lobe.

$$
\begin{gathered}
E_{t x}\left(f_{0}\right)[J]=A_{0}^{2} N \frac{1}{f_{0}} \\
X(f)=\frac{A_{0} N T_{0}}{2} \operatorname{sinc}\left(\left(f-f_{0}\right) N T_{0}\right) e^{-j\left(2 \pi f-2 \pi f_{0}\right) \frac{N T_{0}}{2}} \\
E[J]=2 \int_{<B W>}|X(f)|^{2} d f=2 \int_{f_{0}-\frac{f_{0}}{N}}^{f_{0}+\frac{f_{0}}{N}}|X(f)|^{2} d f \\
E_{t x, B W}\left(f_{0}\right)[J]=A_{0}^{2} N \frac{1}{f_{0}} \frac{\operatorname{Si}(2 \pi)}{\pi}
\end{gathered}
$$




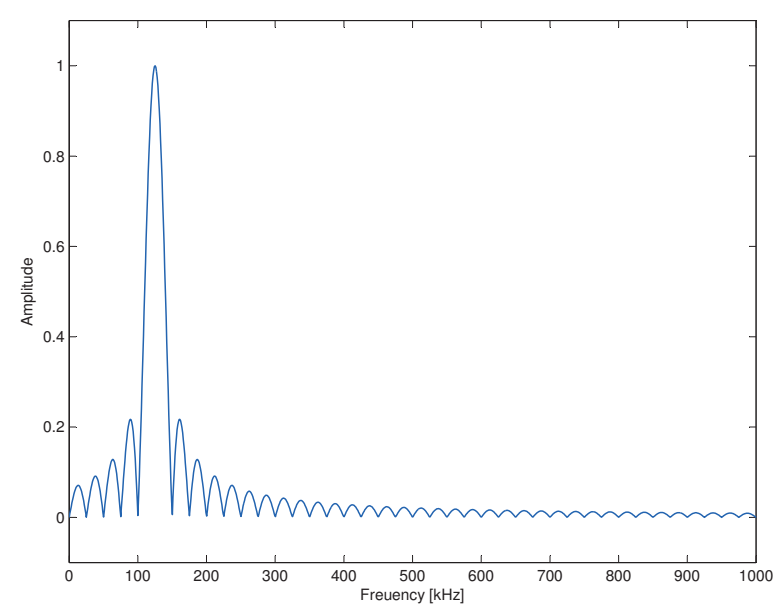

Figure A.2: Normalized magnitude spectrum of tone burst signal $\left(f_{0}=125 \mathrm{kHz}, \mathrm{N}=5\right)$

\section{References}

[1] A. J. A. J. Majumdar, J. Ryder, B. R. S. G. Britain), Glass fibre reinforcement of cement products, Garston, England : Building Research Station, reprinted from: Glass technology, v.9(3), June 1968, 1968.

2] A. Bentur, Fibre reinforced cementitious composites, Taylor \& Francis, ISBN ISBN: 0203088727, 9780203088722, 1990.

[3] A. Majumdar, J. West, L. Larner, Properties of glass fibres in cement environment, Journal of Materials Science 12 (5) (1977) 927-936, ISSN 0022-2461.

[4] L. Larner, K. Speakman, A. Majumdar, Chemical interactions between glass fibres and cement, Journal of Non-Crystalline Solids 20 (1) (1976) 43 - 74, ISSN 0022-3093.

[5] P.-C. Ma, J.-W. Liu, S.-L. Gao, E. MÃd'der, Development of functional glass fibres with nanocomposite coating: A comparative study, Composites Part A: Applied Science and Manufacturing 44 (0) (2013) 16 - 22, ISSN 1359-835X.

[6] S.-L. Gao, E. MÃd'der, R. Plonka, Nanocomposite coatings for healing surface defects of glass fibers and improving interfacial adhesion, Composites Science and Technology 68 (14) (2008) 2892 - 2901, ISSN 0266-3538, nanocomposites - Processing, Characterization, Properties, Applications and Modelling, selected papers from Nanocomposite Special Symposium of ACCM-5, with regular papers.

[7] P. Purnell, N. Short, C. Page, a.J Majumdar, P. Walton, Accelerated ageing characteristics of glass-fibre reinforced cement made with new cementitious matrices, Composites Part A: Applied Science and Manufacturing 30 (9) (1999) 1073-1080, ISSN 1359835X.

[8] S. Leonard, A. Bentur, Improvement of the durability of glass fiber reinforced cement using blended cement matrix, Cement and Concrete Research 14 (5) (1984) 717 - 728, ISSN 0008-8846.

[9] B. Proctor, D. Oakley, K. Litherland, Developments in the assessment and performance of grc over 10 years, Composites 13 (2) (1982) 173 - 179, ISSN 0010-4361.

[10] J. Payá, M. Bonilla, M. Borrachero, J. Monzó, E. Peris-Mora, L. Lalinde, Reusing fly ash in glass fibre reinforced cement: A new generation of high-quality \{GRC\} composites, Waste Management 27 (10) (2007) 1416 - 1421, ISSN 0956-053X, wascon 2006 6th International Conference: Developments in the re-use of mineral waste.

[11] W.-T. Lin, A. Cheng, R. Huang, S.-Y. Zou, Improved microstructure of cement-based composites through the addition of rock wool particles, Materials Characterization 84 (0) (2013) 1 - 9, ISSN 1044-5803.

[12] N. C. V.M. Maholtra, Non destructive testing on concrete, vol. 1, CRC Press, 2004.

[13] J. A. Bogas, M. G. Gomes, A. Gomes, Compressive strength evaluation of structural lightweight concrete by non-destructive ultrasonic pulse velocity method, Ultrasonics 53 (5) (2013) $962-972$.

[14] A. Jain, A. Kathuria, A. Kumar, Y. Verma, K. Murari, Combined Use of Non-Destructive Tests for Assessment of Strength of Concrete in Structure, Procedia Engineering 54 (0) (2013) $241-251$.

[15] T. P. Philippidis, D. G. Aggelis, Experimental study of wave dispersion and attenuation in concrete., Ultrasonics 43 (7) (2005) 584-95, ISSN 0041-624X.

[16] S. Popovics, J. L. Rose, J. S. Popovics, The behaviour of ultrasonic pulses in concrete, Cement and Concrete Research 20 (2) (1990) $259-270$, ISSN 0008-8846.

[17] L. Vergara, J. Gosálbez, J. Fuente, R. Miralles, I. Bosch, Measurement of cement porosity by centroid frequency profiles of ultrasonic grain noise, Signal Processing 84 (12) (2004) 2315-2324.

[18] L. Vergara, R. Miralles, J. Gosálbez, F. Juanes, L. Ullate, J. Anaya, M. Hernández, M. Izquierdo, NDE ultrasonic methods to characterise the porosity of mortar, NDT \& E International 34 (8) (2001) 557-562.

[19] D. Aggelis, T. Philippidis, Ultrasonic wave dispersion and attenuation in fresh mortar, NDT \& E International 37 (8) (2004) 617-631, ISSN 09638695. 
[20] Z. Lafhaj, M. Goueygou, A. Djerbi, M. Kaczmarek, Correlation between porosity, permeability and ultrasonic parameters of mortar with variable water/cement ratio and water content, Cement and Concrete Research 36 (4) (2006) 625-633, ISSN 00088846.

[21] J. N. Eiras, T. Kundu, M. Bonilla, J. Payá, Nondestructive Monitoring of Ageing of Alkali Resistant Glass Fiber Reinforced Cement (GRC), Journal of Nondestructive Evaluation 32 (3) (2013) 300-314, ISSN 0195-9298.

[22] B. Standard, Precast concrete products - Test method for glass-fibre reinforced cement - Part 5. Measuring bending strength, 'Complete bending test' method., 1998.

[23] J. Krautkrämer, H. Krautkrämer, Ultrasonic testing of materials, Springer-Verlag, ISBN 9783540117339, 1983.

[24] P. Gaydecki, F. Burdekin, The propagation and attenuation of medium-frequency ultrasonic waves in concrete: a signal analytical approach, Measurement Science ... 126.

[25] M. Molero, I. Segura, S. Aparicio, M. G. Hernández, M. a. G. Izquierdo, On the measurement of frequency-dependent ultrasonic attenuation in strongly heterogeneous materials., Ultrasonics 50 (8) (2010) 824-8, ISSN 1874-9968.

[26] L. Vergara, J. Fuente, J. Gosálbez, R. Miralles, I. Bosch, Processing of ultrasonic grain noise signals for the estimation of depth-and frequency-dependent attenuation, Measurement Science and Technology 14 (7) (2003) 1018.

[27] S. Soliman, M. Srinath, Continuous and Discrete Signals and Systems, International edition, Prentice-Hall International, ISBN 9780135691120, 1998. 